This item was submitted to Loughborough's Research Repository by the author.

Items in Figshare are protected by copyright, with all rights reserved, unless otherwise indicated.

\title{
The effect of droplet ejection frequency on inkjet-etched micro via holes
}

PLEASE CITE THE PUBLISHED VERSION

http://dx.doi.org/10.1109/EPTC.2010.5702639

PUBLISHER

(c) IEEE

VERSION

AM (Accepted Manuscript)

LICENCE

CC BY-NC-ND 4.0

REPOSITORY RECORD

Zhang, Yan, Changqing Liu, and David C. Whalley. 2019. "The Effect of Droplet Ejection Frequency on Inkjetetched Micro via Holes”. figshare. https://hdl.handle.net/2134/11278. 
This item was submitted to Loughborough's Institutional Repository (https://dspace.lboro.ac.uk/) by the author and is made available under the following Creative Commons Licence conditions.

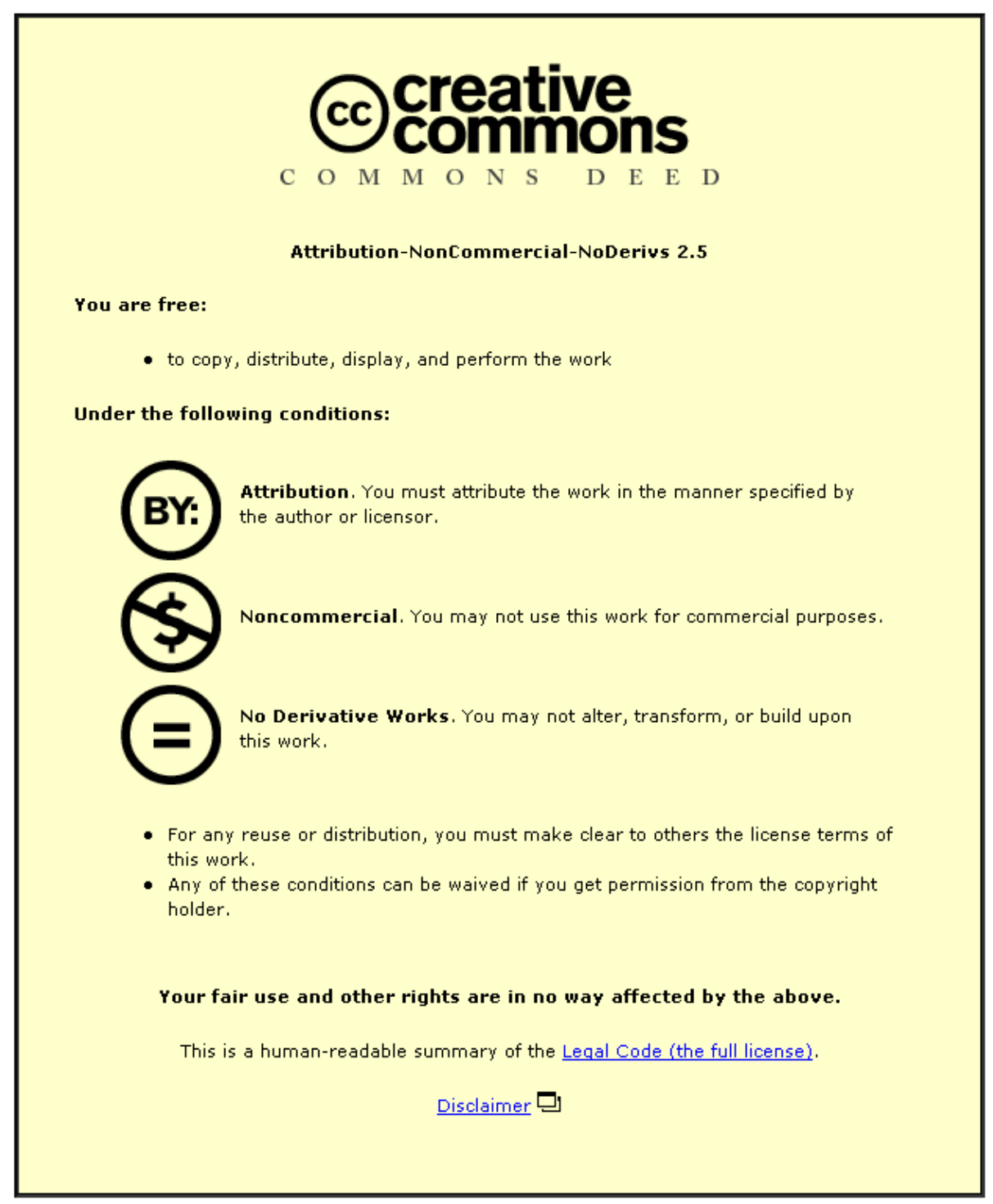

For the full text of this licence, please go to: http://creativecommons.org/licenses/by-nc-nd/2.5/ 


\title{
The Effect of Droplet Ejection Frequency on Inkjet-Etched Micro Via Holes
}

\author{
Yan Zhang, Changqing Liu and David Whalley \\ Wolfson School of Mechanical and Manufacturing Engineering, Loughborough University \\ Loughborough, Leicestershire, United Kingdom, LE11 3TU \\ Email: Y.Zhang6@lboro.ac.uk
}

\begin{abstract}
Inkjet etching has been identified as a potential route to formation of micro via holes in polymer dielectrics. Such v could facilitate three-dimensional integration and sequential build-up fabrication in printed electronics. In the research reported in this paper, ethanol droplets were jetted onto a poly(4-vinyl phenol) (also known as PVP or PVPh) layer at different frequencies in order to observe the effect of droplet ejection frequency on the diameters of the via holes produced. The results demonstrate that via holes remain the same diameter at a low drop ejection frequency, while they enlarge at a relatively high frequency. A mechanism for this behaviour is proposed for which high speed photography provides evidence.
\end{abstract}

\section{Introduction}

Vias, including blind vias, buried vias and through-hole vias, are widely used in printed circuit boards (PCBs) and other forms of electronic packaging to provide connections between the internal and external layers of interconnections. Micro vias (diameter $<150 \mu \mathrm{m}$ ) play a very significant role in chip scale packaging (CSP), wafer level packaging (WLP) and system on package (SoP) due to their great capacity to facilitate compact three dimensional integration in traditional silicon based electronics, which will be increasingly important as semiconductor device miniaturisation approaches its physical limits. On the other hand, plastic electronics are now thriving due to their improving performance and low cost for simple functions. All polymer electronics integration is expected to become a mainstream technology because of its potential for high volume production at low cost. For such applications, vias will also play a key role. In the work described in this paper, a commercially available inkjet printer was utilised to generate ethanol droplets so as to locally dissolve a via hole through a PVPh layer. This method was pioneered for via hole creation by Takeo Kawase, et al, [1] and has been extended into other areas such as flat-panel display applications, [2, 3] or adapted for different applications. [4]

\section{Experimental Set-up}

\section{Materials}

In this study, anhydrous ethanol $(\geq 99.5 \%)$ was used as the dissolving solvent. PVP with a molecular weight $\left(\mathrm{M}_{\mathrm{w}}\right)$ of 11,000 was dissolved into isopropyl alcohol (IPA) using an ultrasonic bath to break up any agglomeration until a clear yellow-coloured solution without obvious existence of agglomerates forms. The concentration of the PVP solution was calculated to be $11.3 w t \%$. $76 \mathrm{~mm} \times 52 \mathrm{~mm}$ microscope slides with a thickness between $1.2 \mathrm{~mm}$ and $1.5 \mathrm{~mm}$ were used as the substrate, onto which the polymer solution was spin coated. The spin coating parameters were set to $1500 \mathrm{rpm}$ and $40 \mathrm{~s}$, resulting in a thickness, $H_{p}$, of about $1.26 \mu \mathrm{m}$ after drying.

\section{Equipment}

A Microfab JetLab 4 inkjet printer was used. The printer was programmed such that 23 holes were created in a single row. The first 20 holes were generated using 1 to 20 drops with an increment of 1 , while for the remaining 3 holes, 30, 40 and 50 drops were dispensed. This arrangement helped to accurately ascertain the changes in diameter early in the hole dissolution process when there is still residual polymer at the bottom of the hole, while avoiding duplication when the polymer layer is penetrated completely. The distance between adjacent printed holes was $1 \mathrm{~mm}$. The via hole produced with this method usually assumes a crater-like appearance. A schematic sketch of the profile of a hole created is shown in Figure 1. and hole features such as the outer diameter and inner diameter are defined as illustrated. The outer diameter, the inner diameter and the hole depth were measured using white light interferometry (WLI).

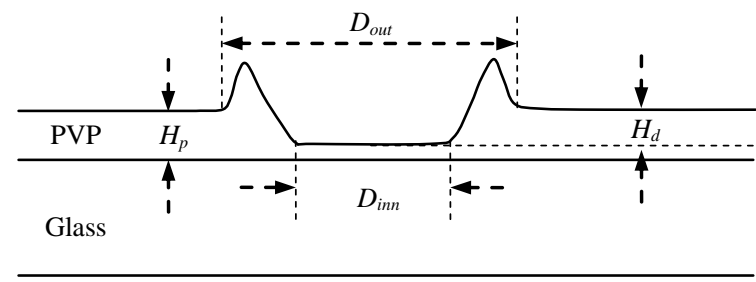

Fig. 1. A schematic illustration of the via hole profile and the definition of hole features

To reduce the possibility of drop deviation, the nozzle was set as close as possible to the substrate. Any pendant drops that formed on the nozzle were removed with cotton swabs to prevent the ejected drops from being disturbed. These are to ensure a good quality of via hole production can be achieved.

\section{Process parameters}

A unipolar waveform was employed to trigger the inkjet head, as shown in Figure 2.. Accessible parameters which have impacts on the droplet formation include rise time $t_{\text {rise }}$, dwell time $t_{d w e l l}$, fall time $t_{\text {fall }}$, the voltage amplitude during the dwell time, $U_{d w e l l}$, and the ink reservoir back pressure. These parameters were tuned so that the camera view on the computer screen showed a perfect solid dark spot, representing an ethanol droplet, against a light background without any satellite tail drops behind it. The strobe delay was adjusted to allow capture of droplet images at various locations in flight to ensure the trajectory of the generated droplet stayed as close to a straight line perpendicular to the substrate as possible. 


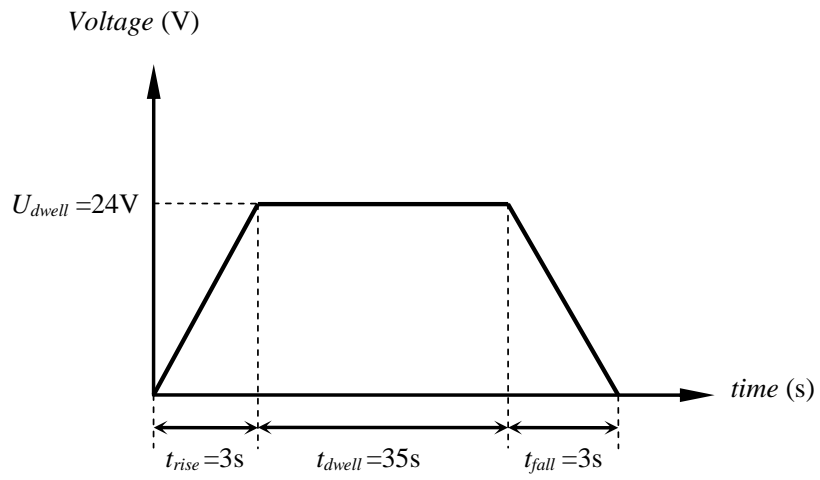

Fig. 2. A schematic illustration of a unipolar waveform used

The rise time, $t_{\text {rise }}$, and fall time, $t_{\text {fall }}$, were both kept at $3 \mu \mathrm{s}$ here, while the dwell time, $t_{d w e l l}$, and the voltage amplitude during $t_{d w e l l}$ were maintained at $35 \mu \mathrm{s}$ and $24 \mathrm{~V}$ respectively. The print head used had a nozzle diameter of $60 \mu \mathrm{m}$. The droplet diameter and volume were estimated using the drop analysis function incorporated in the controlling software to be approximately $40 \mu \mathrm{m}$ and $31.4 \mathrm{pL}$ respectively. The droplet velocity was measured to be about $0.48 \mathrm{~m} / \mathrm{s}$. Droplet ejection frequencies $(f)$ of $1 \mathrm{~Hz}$ and $50 \mathrm{~Hz}$ were used to dispense ethanol drops.

\section{Experimental results}
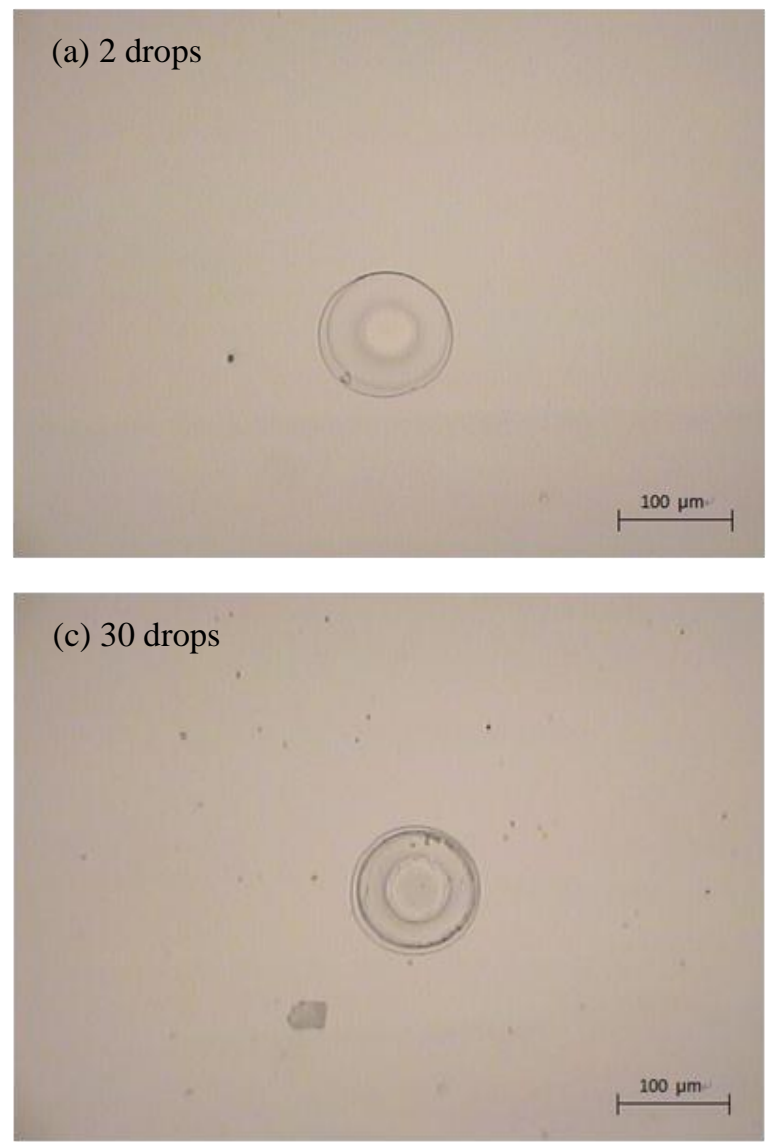

$f=1 H z$

Figure 3. shows images of via holes created at a drop ejection frequency of $1 \mathrm{~Hz}$ by $2,20,30$ and 40 ethanol drops. As can be seen from these photos, the outer diameter remains the same regardless of the number of drops dispensed. This is confirmed by the WLI measurement results. The average outer diameter of via holes produced at $1 \mathrm{~Hz}$ was calculated to be approximately $122 \mu \mathrm{m}$. Ideally the border of the via hole, which is also the pinned contact line of the sessile drop before it evaporates, as defined in Figure 4., should be one circle instead of several. Even though efforts have been taken to minimise any trajectory deviation and retain a better repeatability of drop landing position, experimental results still show more than one contact line for these holes and the circularity becomes progressively worse as the number of drops increases. This can be caused by drop trajectory deviation, inhomogeneous wetting or both.

When only one ethanol drop is jetted onto the polymer layer, it only penetrates the polymer layer down to $0.335 \mu \mathrm{m}$ and the corresponding inner diameter is $63.15 \mu \mathrm{m}$. However, at $1 \mathrm{~Hz}$ when a second droplet lands there and keeps dissolving the hole, the depth increases up to $0.937 \mu \mathrm{m}$ and the corresponding inner diameter shrinks down to $44.6 \mu \mathrm{m}$. After dispensing of several ethanol droplets, the inner diameter eventually stays the same regardless of the number of ethanol droplets dispensed.

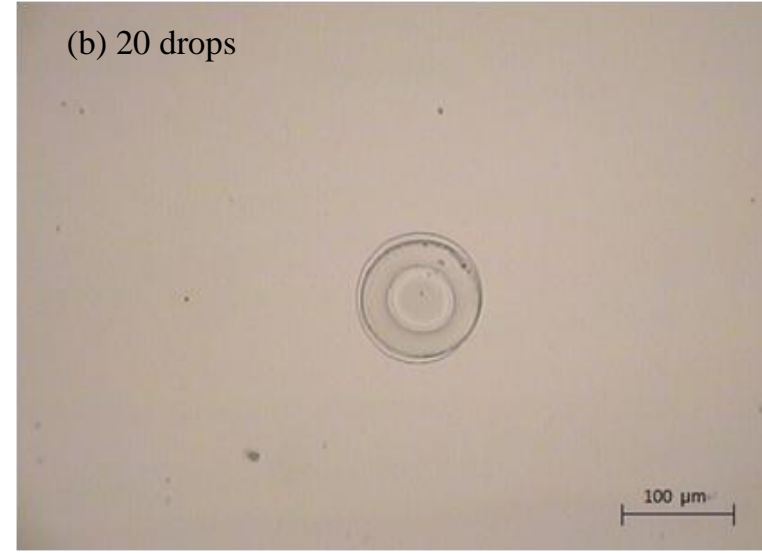

(d) 40 drops

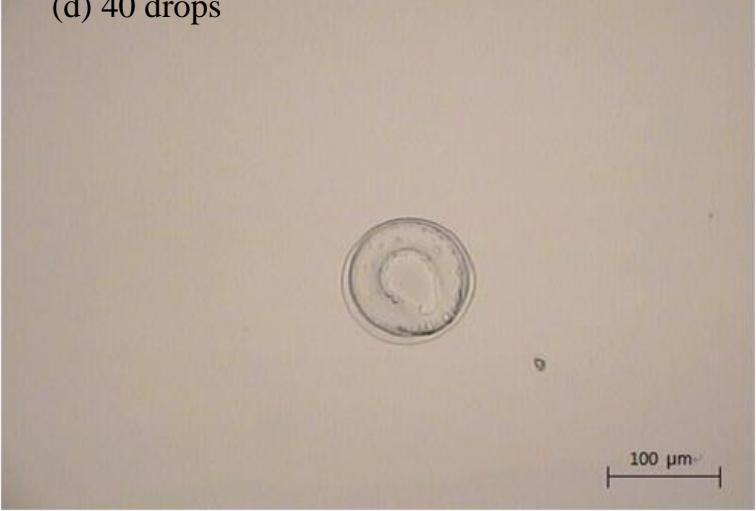

Fig. 3. Optical microscopy pictures of via holes created at $1 \mathrm{~Hz}$ by (a) 2 drops (b) 10 drops (c) 30 drops (d) 40 drops 


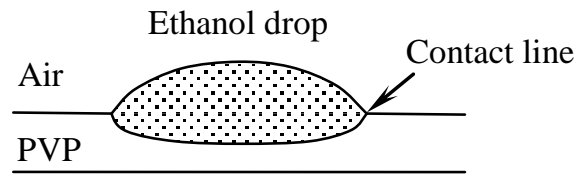

Substrate

Fig. 4. A cross sectional diagram of a droplet showing the contact line

Figure 5 shows the variation of $D_{\text {out }}$ and $D_{\text {inn }}$ with the number of drops dispensed. The average hole depth, $H_{d}$, is calculated using via holes created by 10 drops and more so that they are completely etched through the PVP. $H_{d}$ is calculated to be around $1.27 \mu \mathrm{m}$ for via holes produced at $1 \mathrm{~Hz}$, which is approximately equal to the polymer film thickness.

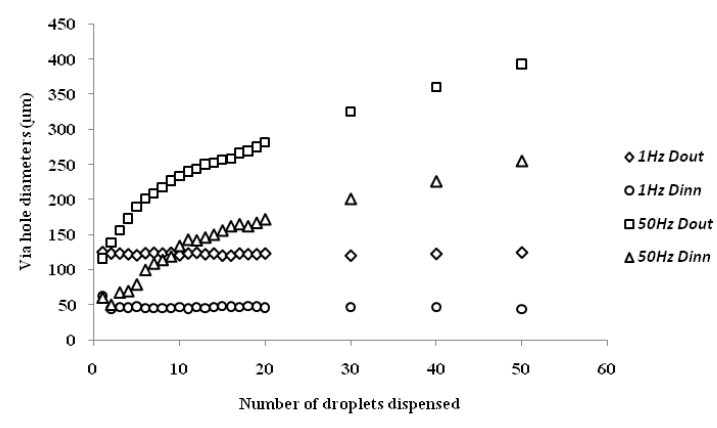

Fig. 5. Outer and inner diameter of hole versus number of drops at $1 \mathrm{~Hz}$ and $50 \mathrm{~Hz}$

$f=50 \mathrm{~Hz}$

For via holes produced at a droplet ejection frequency of $50 \mathrm{~Hz}$, the outer diameter increases with an increase of the number of drops dispensed instead of remaining the same stet at lower frequencies. The average outer diameter for the via hole created by only one ethanol drop and 50 drops is calculated to be $117 \mu \mathrm{m}$ and $394.5 \mu \mathrm{m}$ respectively. The inner diameter follows the outer diameter in a similar way, except that the inner diameter of the hole created by one drop is well above that of those produced by several drops.

The average $H_{d}$ for via holes produced at $50 \mathrm{~Hz}$ is calculated to be $0.74 \mu \mathrm{m}$, far below the thickness of the polymer film, which in turn indicates that via holes produced at a droplet ejection frequency of $50 \mathrm{~Hz}$ are not completely etched and significant polymer residue exists at the bottom of those via holes.

The via hole formation process is reported to rely on an outward material transfer from the centre to the perimeter during the evaporation of the solvent sessile drop, the contact line of which is pinned without movement $[1,5]$. We presume here that at $50 \mathrm{~Hz}$ insufficient time between drops is available for the jetted drop to evaporate so that it merges with subsequent drops into an increasingly bigger one, which leads to continuous enlargement of the sessile drop on the PVP layer. The contact line therefore moves outwards with increasing numbers of ethanol droplets, which is confirmed by our subsequent video recording.

\section{Video recording}

A high speed camera system with microscopic lens was used to record the via hole creation process to observe the sessile drop on a microscopic scale. The camera was placed at a suitable angle to view the via hole. However since the camera was not perpendicular to the feature being observed, the limited depth of field of the lens system meant that only a stripe of the image was in focus. A cold light source was used to provide illumination without generating significant heat, which could influence the drop evaporation. The recording speed was set to $100 \mathrm{fps}$. Figure 6. shows six images at different times from a video recorded for continuous jetting for approximately $2.35 \mathrm{~s}$ at an ejection frequency of $50 \mathrm{~Hz}$.
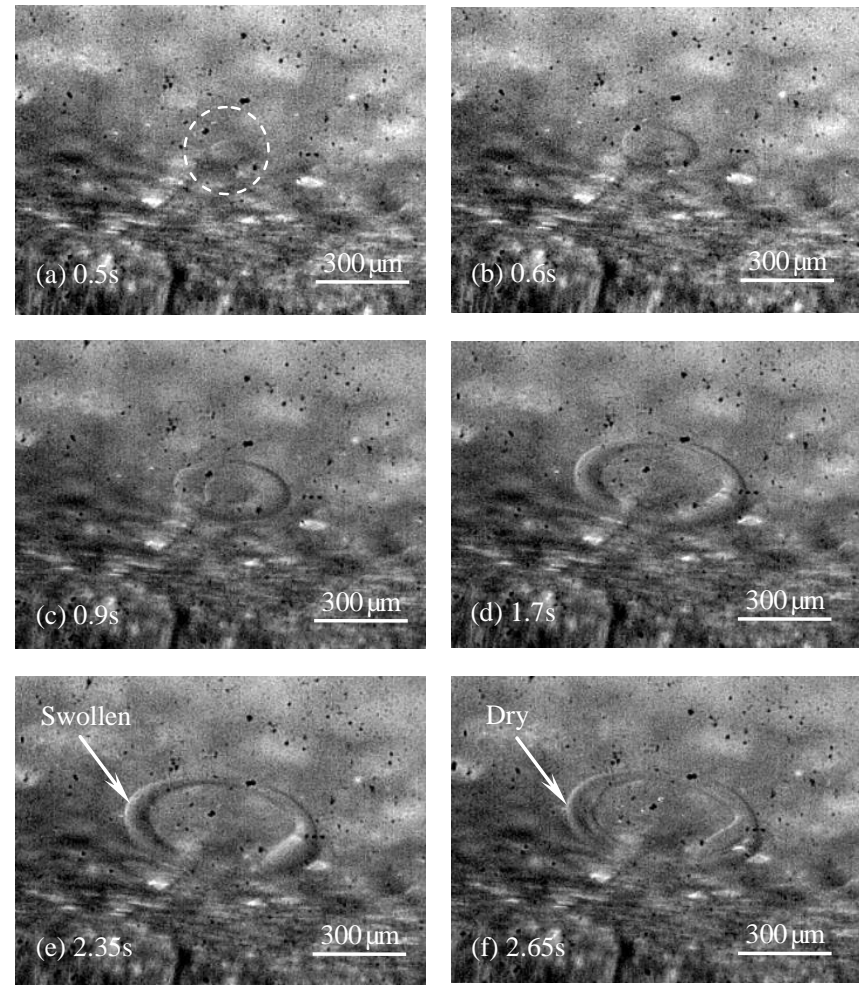

Fig. 6. Images of a via hole produced at $50 \mathrm{~Hz}$ recorded by the high speed camera system

It can be observed from Figure 6. that the outer diameter and inner diameter both rise with an increase of the number of ethanol drops dispensed. Before the jetting is suspended, the ethanol droplets keep joining into the liquid solution with polymer dissolved in. The drop impact and kinetic energy transfer make the contact line move outwards instead of being pinned locally, enlarging the size of the via hole. Jetting terminates at $2.35 \mathrm{~s}$ and the solvent can then evaporate without any more drops merging in. This is revealed by the perimeter of the via hole becoming less swollen, as shown in Figure 6. (f).

\section{Summary}


An inkjet printer was used to produce via holes by dispensing ethanol on to a PVP coated glass substrate. After waveform optimisation to generate uniform droplets following a straight trajectory, different dispensing frequencies were employed to jet ethanol onto the PVP layer. At $1 \mathrm{~Hz}$, the outer diameter was found to stay the same regardless of the number of drops used to dissolve the via hole, while the inner diameter also remains the same after the first few drops. The bottoms of the via holes produced at $1 \mathrm{~Hz}$ are presumed to be completely revealed, based on a comparison between the polymer film thickness and the via hole depth. However further conductivity tests are still needed to confirm whether there is any residual polymer left. Both $D_{\text {out }}$ and $D_{\text {inn }}$ grow with the number of ethanol drops at $50 \mathrm{~Hz}$. The average hole depth is calculated to be close to $0.74 \mu \mathrm{m}$, much less than the PVP film thickness, which reveals that via holes created at $50 \mathrm{~Hz}$ are not completely etched and significant polymer residue exists in the holes. The hole enlargement is attributed to the relationship between droplet volume and evaporation. A high speed camera was used to observe the process. And the recorded video shows that at a high droplet ejection frequency, a sessile drop remains while jetting continues.

\section{Conclusion}

At low droplet ejection frequencies, both inner and outer diameters remain unchanged regardless of the number of drops dispensed, while they both enlarge with an increasing number of drops at high frequencies. Different scenarios correspond to different relation between solvent evaporation and the remaining sessile drop volume. We presume there is a threshold frequency under which no via hole enlargement will occur. Effort will be made to further confirm this and find the threshold frequency for a droplet of a specific volume if applicable.

\section{Acknowledgments}

We would like to thank the EPSRC Mintegration Project for funding and the EPSRC Engineering Instrument Pool for loan of the high speed camera system for this research work.

\section{References}

1. T. Kawase, H. Sirringhaus, R.H. Friend, and T. Shimoda, "Inkjet Printed Via-Hole Interconnections and Resistors for All-Polymer Transistor Circuits," Advanced Materials, Vol. 13, No. 21 (2001), pp. 16011605.

2. Y. Xia and R. H. Friend, "Nonlithographic Patterning through Inkjet Printing Via Holes," Applied Physics Letters, Vol. 90, (2007), pp. 253513-1-253513-3.

3. Berend-Jan de Gans, S. Hoeppener, and U.S. Schubert, "Polymer-Relief Microstructures by Inkjet Etching," Advanced Materials, Vol. 18, (2006), pp. 910-914.

4. A.J. Lennon, A.W.Y. Ho-Baillie, S.R. Wenham, "Direct Patterned Etching of Silicon Dioxide and Silicon Nitride Dielectric Layers by Inkjet Printing," Solar Energy Materials and Solar Cells, Vol. 93, (2009), pp. 18651874.

5. R.D. Deegan, O. Bakajin, T.F. Dupont, G. Huber, S.R. Nagel, and T.A. Witten, "Capillary Flow as the Cause of Ring Stains from Dried Liquid Drops," Nature, Vol. 389, (1997), pp. 827-829. 